\title{
Mitigating Climate Change Impact through Technology Dissemination
}

\author{
D. Raji Reddy and B. Savitha* \\ Professor Jayashankar Telangana State Agricultural University \\ Hyderabad, Telangana, India \\ *Corresponding author
}

Keywords

Rainfall,

Temperature,

Radiation, Wind,

Soil health

Article Info

Accepted:

07 September 2019

Available Online:

10 October 2019
India is blessed with excellent natural resources like, soil, water and climatic conditions. Climate change is a significant variation in weather patterns occurring over periods ranging from decades to millions of years. Climate change impacts on agriculture are being witnessed all over the world, but countries like India are more vulnerable in view of the huge population dependence on agriculture, excessive pressure on natural resources and poor coping mechanisms. Adaptation interventions for climate resilient agriculture require interdisciplinary, multifunctional approach with a strong mechanism for finance; capacity building and technology transfer are prerequisites for success. To mitigate the climate change impact, various strategies were tested in the field through university extension system and a few of the strategies found success are discussed here under. Key words: Climate change, mitigation strategy, innovative technologies

\section{Introduction}

Climate is emerging as a prominent issue in the world nowadays. The climate has changed, is changing and will continue to change regardless of what investments in mitigation are made. Climate change is a significant variation in weather patterns occurring over periods ranging from decades to millions of years. Climate change impacts on agriculture are being witnessed all over the world, but countries like India are more vulnerable in view of the huge population dependence on agriculture, excessive pressure on natural resources and poor coping mechanisms. The effects of climate change have reached such an extent that irreversible changes in the functioning of the planet are feared, hence enhancing resilience will form the key aspect of the challenge at hand (Venkateswarlu and 
Shanker, 2009; Singh et al., 2012). The effects of climate change on agriculture will differ across the country, determining how climate change sill affect agriculture is complex; a variety of effects are likely to occur.

Agriculture is the most vulnerable and sensitive sector affected by Climate change because of its dependency on local climate parameters like rainfall, temperature, radiation, wind, soil health etc., to alleviate the challenges posed by climate change.

In India, significant negative impacts have been implied with medium term (2010-2039) climate change, predicted to reduce yields by 4.5-9\%, depending on the magnitude and distribution of warming. Since agriculture makes up roughly $16 \%$ of India's GDP, a $4.5 \%$ negative impact on production implies a cost of climate change to be roughly up to $1.5 \%$ per year (Venkateswarlu et al., 2013)

Resilience to climate change in agriculture refers to the ability to endure harsh and unpredictable environment and effectively bounce back from the negative effects at the earliest. Resilient agriculture will essentially involve judicious and improved management of natural resources viz., land, water, soil and genetic resources through adoption of best management practices. The potential adaptation strategies include better weather forecasting, developing cultivars tolerant to cold/heat temperatures, salinity stress, resistant to flood and drought, modifying crop management practices, improving water management, adopting new farm techniques, crop diversification, improving pest management, and crop insurance and harnessing the indigenous technical knowledge of farmers

Agriculture has to become "Climate Smart", that is, sustainability increase in agriculture productivity and income, adapt and build resilience to climate change, and reduce or remove green house gases emission, wherever possible. Despite the recognised importance of Climate Smart Agriculture, the dissemination and uptake of climate smart technologies, tools and practices is still largely an ongoing and challenging process. The adaptation of climate related knowledge, technologies and practices to local conditions, promoting joint learning by farmers, researchers, extension worker and widely disseminating CSA practices, is critical. Education, training and rural extension services can help in adaptation endeavours. Better weather forecasting and improved communication can assist in contingency planning.

\section{Farmer's perception on Climate change}

Farmer's perception on climate change forms an important part of the dissemination programmes as extension workers need to know what the farmers know in order to give them the appropriate knowledge and technological information in relation to adaptation and mitigation to climate change. In a study conducted by the All India Coordinated Research Project on Agrometeorology (AICRPAM), it was found that majority of the farmers opined rainfall and temperature as the crucial weather parameters that determines the crop productivity (Rao et al., 2011) and in another pilot study conducted in four villages of Uttarakhand, farmers felt that rainfall had declined in quantity and timely onset on monsoon could no longer be relied on and they also observed decline in ground water with increase in heat intensity (Kelkar et al., 2008). Further, in a study conducted in Tamilnadu showed that, respondent farmers observed decrease in quantity of rainfall received over the years along with delay in onset of monsoon. They also felt that the monthly frequency of rains had decreased with increased dry spells (Vardan and Kumar, 
2014). Enhancing climate resilience in agriculture involves the integration of adaptation, mitigation and other practices in agriculture that increase the capacity of the farmer and his production system to respond to various climate related disturbances by resisting or tolerating the damage and recovering quickly and there is a need to improve their capacity to plan for adaptation to evolving climatic conditions and induce a change in local practices. In addition, the successful adoption of climate resilient farming practices will largely depend on the farmer's perception of income gains from the new technologies, as profitability remains the most important incentive for change at farm level.

\section{Preparing for Climate change}

In the future, population growth without significant improvement in yield rates will mean more land must be used for rice cultivation and other crop production, and an increase in the number of farm animals.

These factors will lead to an increase in $\mathrm{CH}_{4}$ and other green house gases released to the atmosphere. Adjustments will be necessary in order to counterbalance any negative impacts of a changing climate. Farmers must have the ability to adjust to changes in crops and crop varieties, improved water management and irrigation system, and changes in planting schedules and tillage practices will be important in limiting the negative effects and taking advantage of the beneficial effects of changes in climate. More efficient use of mineral fertilizers and other adjustments in agricultural practices could also act to counteract the effects of climate change.

Various types and levels of technological and socioeconomic adaptations to climate change are possible. The extent of adaptation depends on the affordability of such measure. Recent national studies show that increased costs of agricultural production under climate change scenarios would be a serious economic burden for some developing countries. Other important factors will be access to know-how and technology, the rate of climate change, and biophysical constraints such as water availability, soil characteristics and crop genetics.

\section{Role of agricultural extension in preparing farmers for mitigating climate change}

Extension wing of the PJTSAU uses various measures to advice the farmers on adapting to climate change by packaging climate change adaptation information into advice on other production challenges that are of immediate importance to the farmers. They thus advice farmers on enterprise choice, help initiate activities that counteract climate change impacts such as afforestation, set up conservation efforts, promote drought resistant crops, passing new farming techniques to the farmers and making the farmer willing to adopt. There is a need to set up Climate Outlook Forum discussion interface at the state level involving all climate sensitive sectors.

The Krishi Vigyan Kendras (KVKs) and District Agricultural Advisory and Transfer of Technology Centre (DAATTCs) of the University are actively involved in creating awareness and demonstrating the coping technologies developed for the benefit among the farming community of the State of Telangana. In addition to this, Krishi Vigyan Kendra, Wyra, Khammam district, Telangana is identified as one of the KVKs in Telangana to implement National Innovation on Climate Resilient Agriculture (NICRA) by the ICAR. The innovative approach adopted in NICRA to achieve Climate Resilient Agriculture famer's participatory approach has shown great promise in climate proofing of Indian Agriculture. 


\section{Agromet advisory services of the University}

Information on impending weather 3-10 days in advance is vital for effectiveness of modern farming practices like sowing weather sensitive high yielding varieties, need based application of fertilizers, pesticides, insecticides irrigation and harvest planning. Medium range forecasts are being issued by the Indian Meteorological Department for the benefit of the farming community. Presently, the IMD provides value added district specific medium range weather forecasts on rainfall, cloud cover, temperature, wind and relative humidity valid for coming 5 days on every Tuesday and Friday. Based on the forecast, Agro Climatic Research Centre (ACRC) of University prepare tendency in maximum and minimum temperatures, wind speed and direction, cloud amount and relative humidity valid for next 5 days beginning 8.30 a, on Tuesday, by looking into the local conditions. On the basis of local agro meteorological and farming information and the weather forecasts form IMD, the DAATTC and KVK scientists discuss bout the options and consequent effects, and then decide the advice for the action by the farmers in respect of the items related to their expertise. All these together constitute the advisory, which also serve an early warning function, alerting farmers to the implications of various extreme weather events such as Tropical cyclone, Storm surge, Heat wave, Flash floods, Hailstorm, Drought etc.

Demonstration and Dissemination of Climate Coping Technologies - SUCCESS Stories of KVKs of the University

Successful technology on Performance of short duration and Salinity tolerant rice variety Siddi (WGL-44)

Most of the farmers in the NICRA adopted village cultivating rice as kharif season crop are facing salinity problem. In addition to this they are cultivating long duration paddy varieties with low productivity potential.

Keeping this in view, the Krishi Vigyan Kendra (KVK) Wyra, Khammam, introduced a rice variety having salinity tolerance. Rice variety - Siddi (WGL 44) is short duration fine grain and salinity tolerant which was also tolerant to gall midge with high yield potential.

Economic analysis showed that Siddi rice variety brings an additional yield of 400 $\mathrm{kg} / \mathrm{acre}$ and an additional income of about Rs. 8,562/- per acre than long duration variety cultivated by the farmers of the region.

\section{Successful technology on water saving in rice}

In general, large amount of water is required for rice cultivation. To educate the farmers about economic use of the water in rice cultivation, to create awareness on water use efficiency and to reduce the cost of cultivation; water saving technologies rice cultivation - broadcasting method was introduced.

Wherein, seed requirement is $10 \mathrm{Kg} /$ acre and crop duration was also shortened by 10-15 days, which in turn resulted in reduced cost of cultivation and increased output recorded $\mathrm{C}: \mathrm{B}$ ratio of $1: 1.3$

\section{Dry converted wet rice - Success story}

In Khammam district, most of the farmers are following conventional method of rice cultivation i.e., transplanting method under tanks and canals as source of irrigation. Due to monsoon vagaries, deficit rain fall and delayed \& limited release of irrigation water from canals, farmers are facing water shortage problem. 
The sustainability of rice eco-system and the ability to increase production in pace with population growth with reduced water and labour use are become major concerns.

Keeping this in view, Krishi Vigyan Kendra (KVK) Wyra, Khammam introduced direct method of rice cultivation like dry converted wet rice. Dry converted wet rice is an alternate to transplanted rice which facilitates the farmers addressing irrigation water shortage and labour scarcity issues of rice cultivation.

In dry converted wet rice cultivation, continuous submergence of field is not necessary, it requires irrigation at critical stages only thus saving water up to $40-50 \%$ and crop comes to maturity around 7-10 days early when compared to transplanted method.

Economic analysis showed that aerobic rice brings an additional income of about Rs. $5,107 /$ - per acre than transplanted rice, from about 6000 ha of area a saving of Rs. 7.66 Crores has been achieved.

\section{Promotion of square planted red gram as an alternative crop to cotton in rain fed red soils}

Inspite of creating awareness through various means the farming community of the State of Telangana cultivating Cotton in rainfed light soils which are a non remunerative practice and resulting in poor performance of crop and low yields. As an alternate crop to commercial cotton crop; redgram is being promoted for cultivation in light soils by adopting square planting method with $90 \mathrm{~cm}$ x $90 \mathrm{~cm}$ spacing.

Economic analysis showed that, redgram cultivation as an alternate to cotton brings an additional income of about Rs. 20,510/- per acre when compared to cultivation of cotton in rain fed red soils. It is a boon to the rain fed farmer.
Farm ponds - climate resilient technology for sustainable agriculture

Rainfed agriculture constitutes $55 \%$ of net sown area in the country. The annual average rainfall of the country varies from 400 to more than $2000 \mathrm{~mm}$ varying in both space and time. In low to medium rainfall rainfed regions, the occurrence of high intense rainfall events with short duration is very common causing the soil erosion. Hence, the efficient rain water management is necessary to improve water productivity and protect the natural resource base in rainfed regions. Farm pond technology has very good potential for implementation in different schemes of state or central government.

Farm Pond is a dug out structure with definite shape and size having proper inlet and outlet structures for collecting the surface runoff flowing from the farm area. It is one of the most important rain water harvesting structures constructed at the lowest portion of the farm area. The stored water must be used for irrigation only. A farm pond must be located within a farm drawing the maximum runoff possible in a given rainfall event.

Farm ponds have a significant role in rainfed regions where annual rainfall is more than or equal to $500 \mathrm{~mm}$. If average annual rainfall (AAR) varies between 500 to $750 \mathrm{~mm}$, the farm ponds with capacity of 250 to $500 \mathrm{~m} 3$ can be constructed. If AAR is more than 750 $\mathrm{mm}$, the farm ponds with capacity more than $500 \mathrm{~m} 3$ can be planned particularly in black soil regions without lining. It was observed from the field experience and if present rainfall pattern changes; at least two to three rainfall events producing considerable runoff are possible in a season making farm ponds an attractive proposition.

In farm pond villages, after excavation of farm pond; cropped area increased and farmers 
utilized harvested water for supplemental irrigation during critical stages of cotton, chilli and oil palm. In addition to this, by rearing fish in farm pond an additional income of Rs. 42 , 500/- was recorded by the practicing farmers.

\section{Raised bed method of turmeric cultivation}

Turmeric is the second most important spice crop cultivated in Nizamabad, Warangal districts of the Telangana state. Traditionally farmers cultivate turmeric crop by ridge and furrow method, where there is a chance for stagnation of excess water favouring the infestation and spreading of rhizome rot disease. In order to overcome this problem, KVKs, Malyal \& Rudrur introduced innovative raised bed method of turmeric cultivation, which led to realization of higher yield with good quality produce.

Economic analysis showed that, raised bed method of turmeric cultivation brings an additional income of about Rs. 38,550/- per acre than ridge \& furrow method with $\mathrm{C}: \mathrm{B}$ ratio of 1.0:2.22.

\section{Sunhemp seed production - Success story in NICRA Village}

Cultivation of Sun hemp after Kharif rice under NICRA project in 16 ha area. Farmers got an average yield of $10 \mathrm{q} / \mathrm{ha}$ with net returns of Rs. 30,750/ha. Sun hemp is leguminous crop and also used for fodder purpose. Sun hemp is drought tolerant crop and is giving good yields even under terminal drought conditions. More than $60 \%$ of farmers in the village have adopted this practice.

Direct seeded rice - Drum seeder technology

Most of the farmers are following conventional method of cultivating rice i.e., transplanted rice under tanks and canals as source of irrigation. Receipt of deficit rainfall, delayed and limited release of irrigation water from canals is the major concerns of the rice cultivating farmers. Therefore, the sustainability of rice eco-system and the ability to increase production in pace with population growth with reduced water and labour use are major concerns.

Keeping this in view, Scientists of KVKs \& DAATTCs of the PJTSAU popularized direct seeding method of rice cultivation with drum seeding to reduce the cost of cultivation, increases net returns and also to conserve the natural resources.

Direct seeding with drum seeder requires low seed rate i.e., 8-12 $\mathrm{Kg} / \mathrm{acre}$ and crop comes to maturity 7-10 days early when compared to transplanted method. Economic analysis showed that, direct seeded rice brings an additional income of about Rs. 3,916/- per acre than transplanted rice.

Rolling stem applicator- An eco-friendly, low cost, input saving and drudgery reducing tool for managing sucking pests of cotton

The University through its DAATTCs and KVKs recommended and popularized stem application - an eco-friendly, low cost, input saving and drudgery reducing technology for management of sucking pests.

A drudgery reducing and low cost insecticide applicator, rolling stem applicator was designed and demonstrated for management of sucking pests of Cotton by KVK, Wyra PJTSAU, Telangana. This technology is popular in state of Telangana and 7 district of the Andhra Pradesh. It is a drudgery reducing, cost effective, time and water saving ecofriendly tool, costs only Rs 200-00 (Rupees Two hundred only). For the management of 
sucking pests in Cotton, stem application of monocrotophos@1:4 and imidacloprid (1:20) was effective in reducing the incidence of the aphids, thrips, jassids. The technology was demonstrated with nearly 842 farmers covering 960 ha of Cotton crop by KVK, Wyra and it was found that, nearly Rs. 300-00 saving in plant protection cost per each application when compared to foliar sprays. The farmers were very much satisfied with the performance of tool. It can be utilized effectively for the management of sucking pests in other crops like Tobacco, Bhendi, Beans, Marigold and can also be used for whorl application of granules and insecticide in Maize, other operations like pruning, cleaning, levelling operations.

\section{Zero tillage in maize cultivation}

Under the changing climate scenario the limitations of rising temperature during grain filling of rice, declining yield of rice and water scarcity affecting yield of Rabi rice, maize being a photo-insensitive crop has better options for adaptation and mitigation of these climatic changes.

Maize is emerging as a potential driving force for diversification i.e. diversification of ricerice with rice-maize and other maize based high value cropping systems in water scarcity/lowering of water table is a major concern in rice growing belt of State and making rice cultivation non-remunerative. Therefore, it Hence, maize has emerged as a potential as well as profitable crop in these areas.

In view of the changing farming scenario in the country, maize has been emerging as one of the potential crops that addresses several issues like food and nutritional security, climate change, water scarcity, farming systems, bio-fuel etc. Further, a recent study by National Centre for Agricultural
Economics and Policy Research (NCAP) has showed that there is an increasing demand for maize in the industry sector which caters to consumer needs like textiles, paper, glue, alcohol, confectionery, food processing and pharmaceutical industry etc., of which the demand keeps on increasing with population pressure.

Maize can be successfully grown without any primary tillage under no-till situation with less cost of cultivation, higher farm profitability and better resource use efficiency. Under such condition one should ensure good soil moisture at sowing and seed and fertilizers should be placed in band using zerotill seedcum-fertilizer planter with furrow opener as per the soil texture and field conditions. The technology is in place with large number of farmers particularly under rice-maize and maize-wheat systems in peninsular and eastern India. However, use of appropriate planter having suitable furrow opener and seed metering system is the key of success of the no-till technology.

University, with the help of DAATTCs and KVKs demonstrated and popularized the technology among the farming community. The Economic analysis showed that, Zero till method of maize cultivation saves investment on cultivation to about Rs. 4,570/- per acre than normal sowing method with $\mathrm{C}: \mathrm{B}$ ratio of 1.0:4.90.

Reduced cost of cultivation (up to Rs. 5,000/per acre) and high net returns (up to Rs. $11,000 /$ - per acre) led to wide spread of the technology in the State.

The glaring reality of climate change manifested in the forms of increasing temperature, frequent droughts, erratic rains, receding glaciers, rising sea levels etc. has necessitated the urgent need to devise appropriate adaptation strategies to sustain 
agriculture for the livelihood of mankind. The role of Agriculture extension advisory services in general and dissemination of technology in particular in agricultural adaptation to climate change is paramount and innovations in methods of dissemination are the need of the hour now in India as well as the most developing world (Meera et al., 2012).

There are a number of agricultural practices and technologies that enhance food security, resilience, and productivity in a sustainable manner. These include on-farm practices such as those relating to management of soil, water, crops, livestock, forests and fisheries, as well as beyond farm interventions such as agricultural extension systems, meteorological services, and crop and livestock insurance.
The agricultural sector has rich experience in designing and implementing agricultural practices and technologies, drawing upon scientific and indigenous knowledge (Credan et al., 2012). This means that designing context-specific interventions is achievable; however strong mechanisms for capacity enhancement and technology transfer are prerequisites for success.

On -the- ground implementation of extension also needs to go hand- in- hand with advocacy and awareness raising of decision makers on the imminent threat of climate change for agriculture in order to make extension more responsive to climate change and contribute to address the triple challenge of food security, adaptation and mitigation (Fig. 1-11).

Fig.1

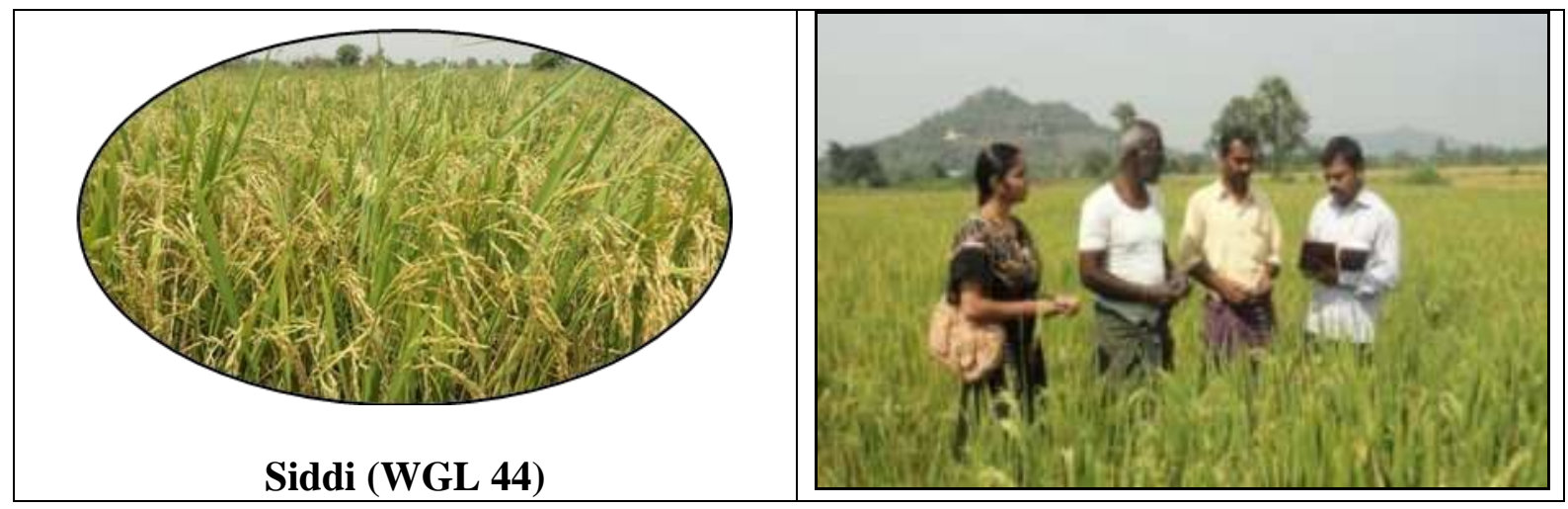

Fig.2

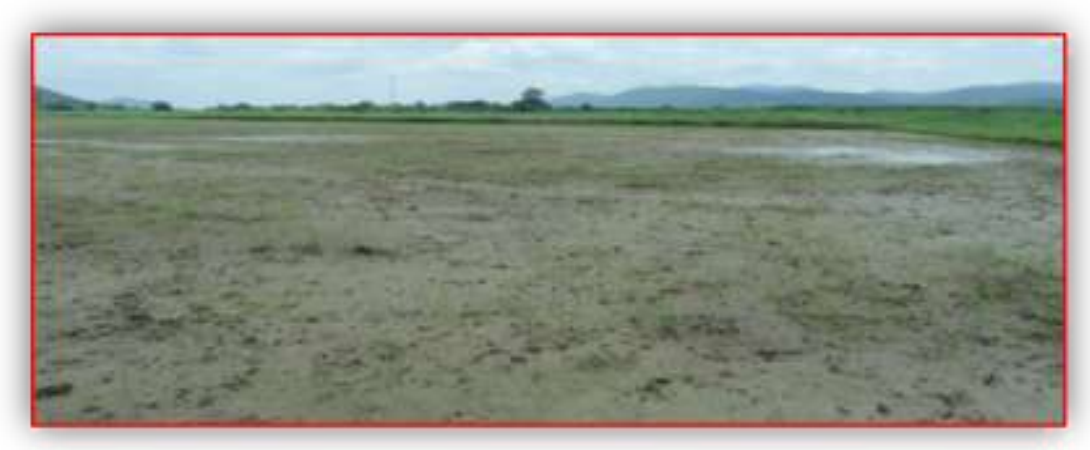

Broad casted paddy field 
Int.J.Curr.Microbiol.App.Sci (2019) 8(10): 823-834

Fig.3

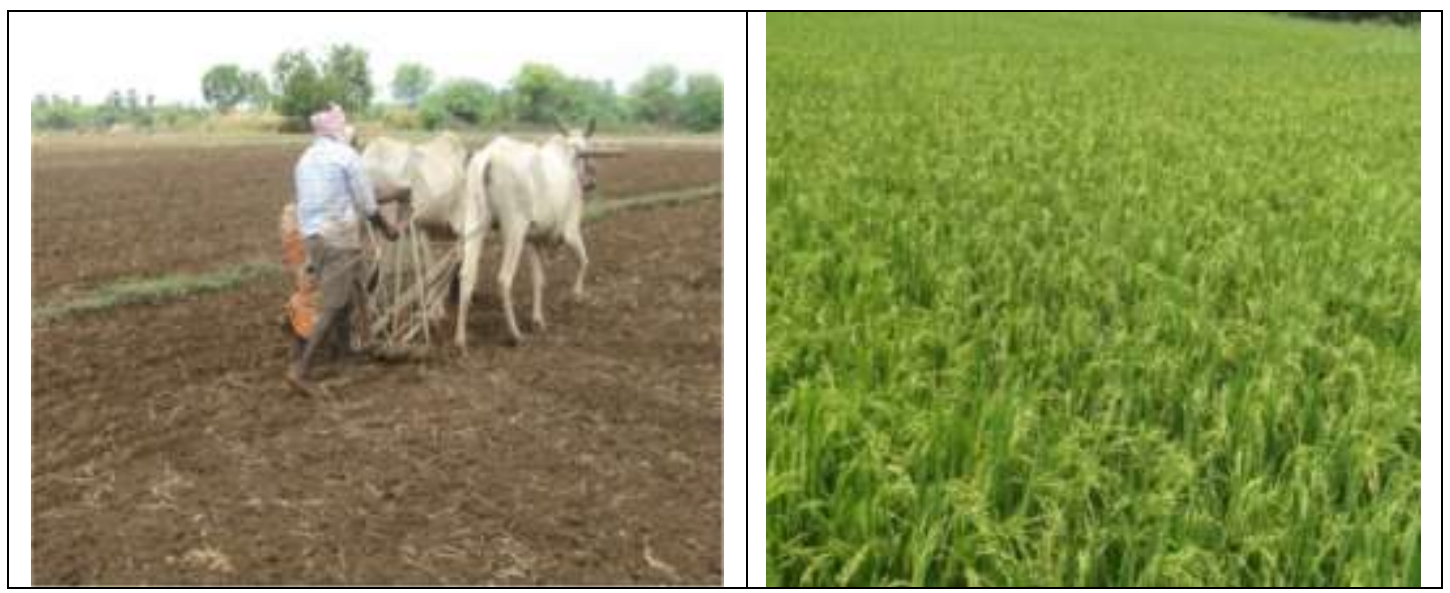

Fig.4

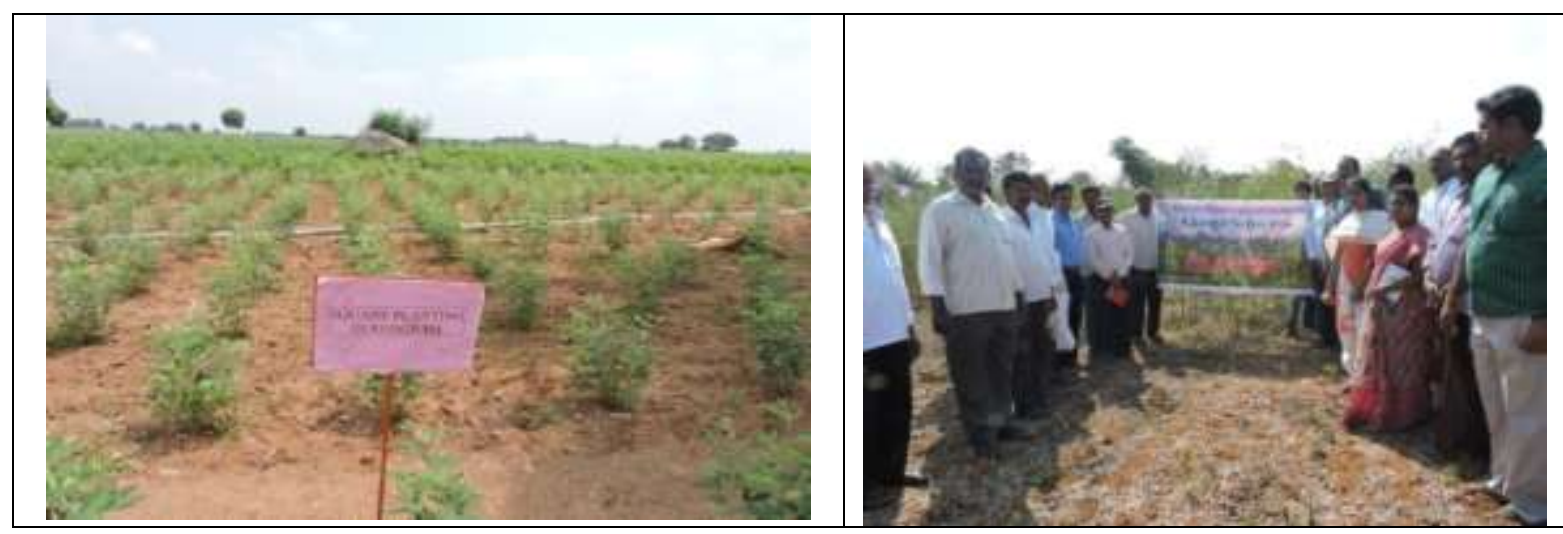

Fig.5
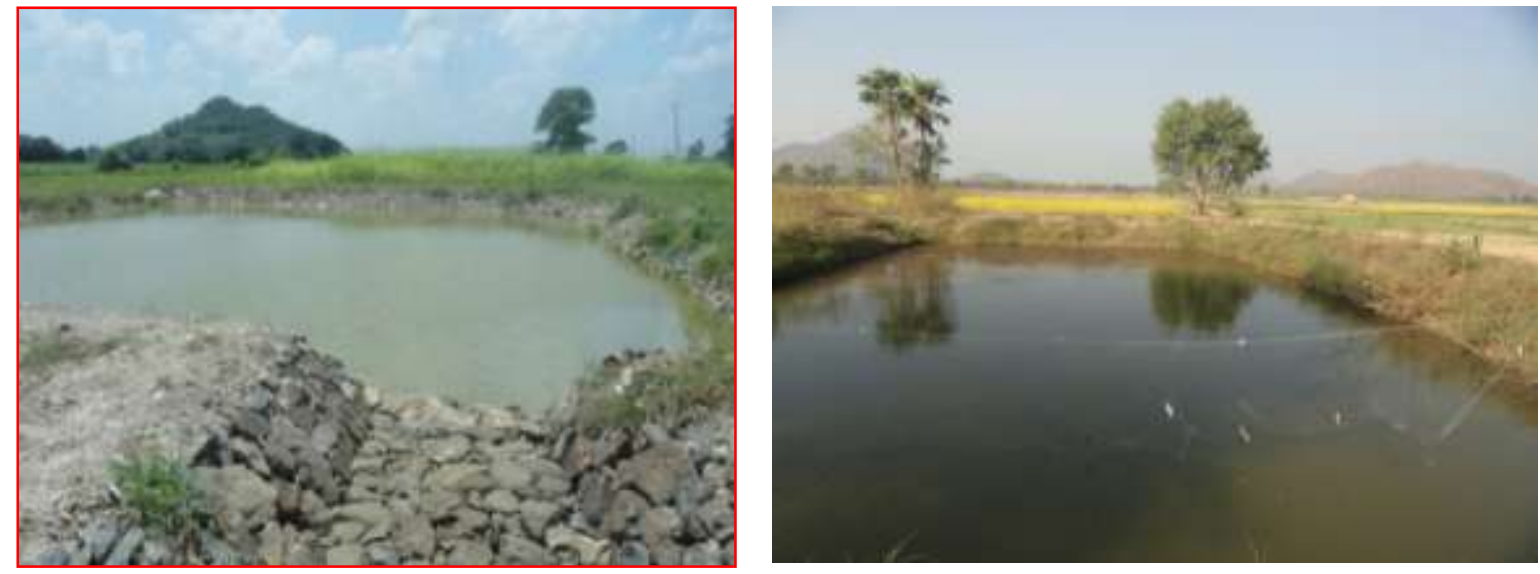
Int.J.Curr.Microbiol.App.Sci (2019) 8(10): 823-834

\section{Fig.6}
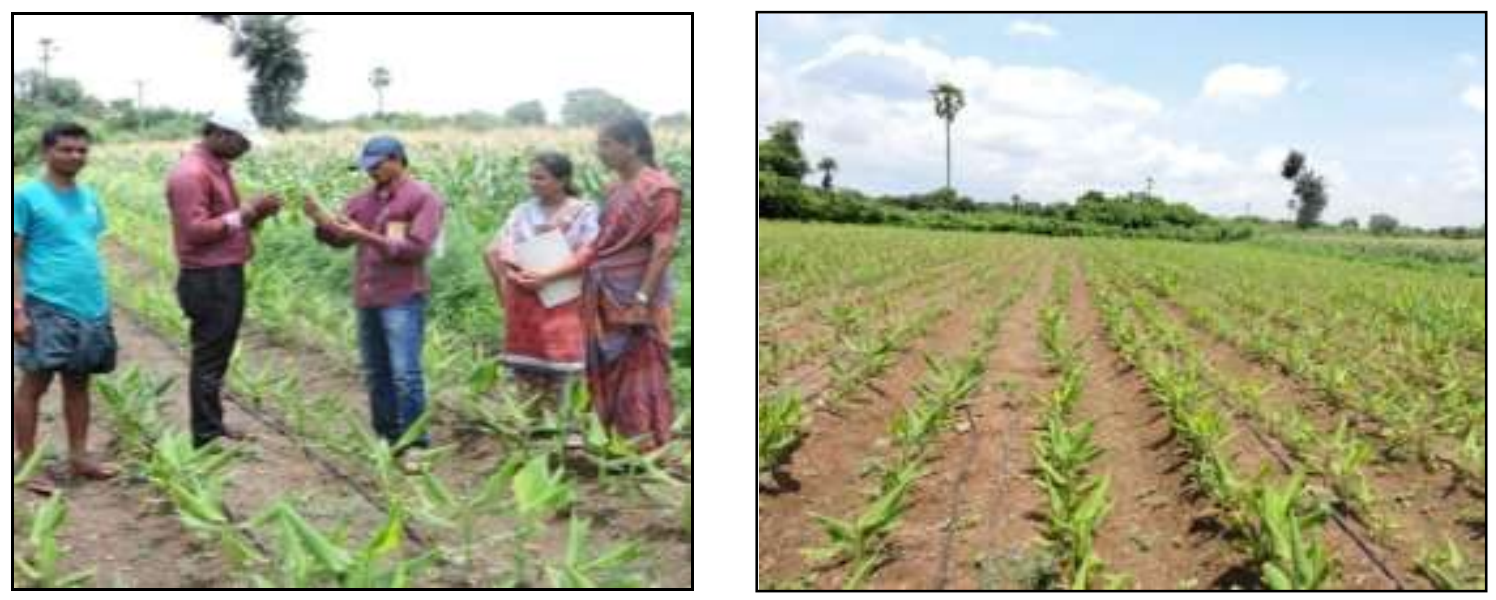

Fig.7
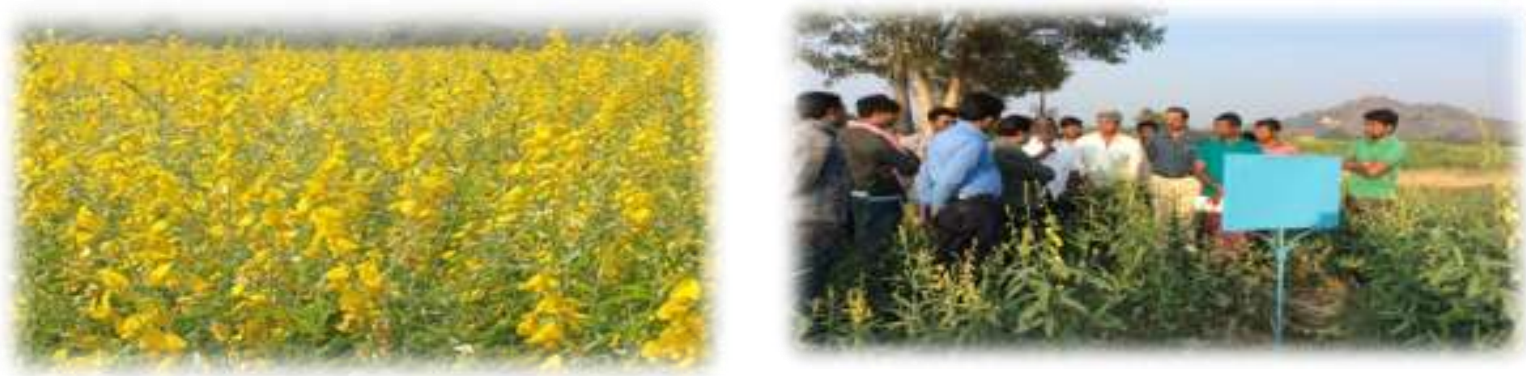

Fig.8
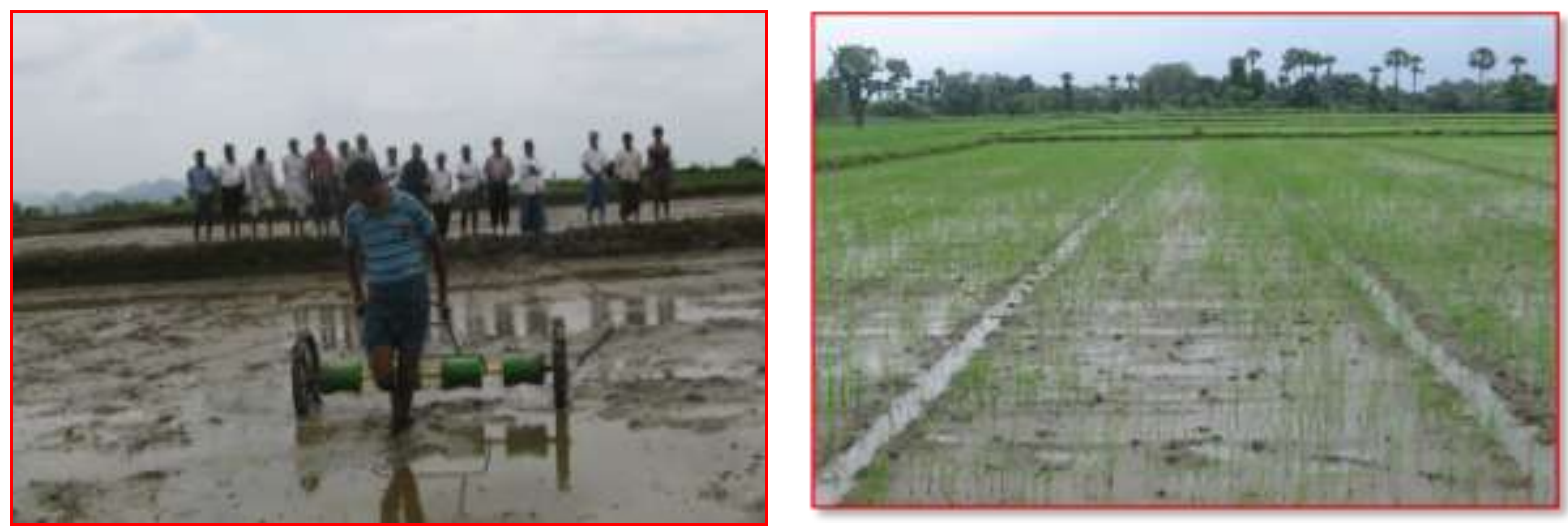
Fig.9 Attachments of multipurpose Rolling stem applicator

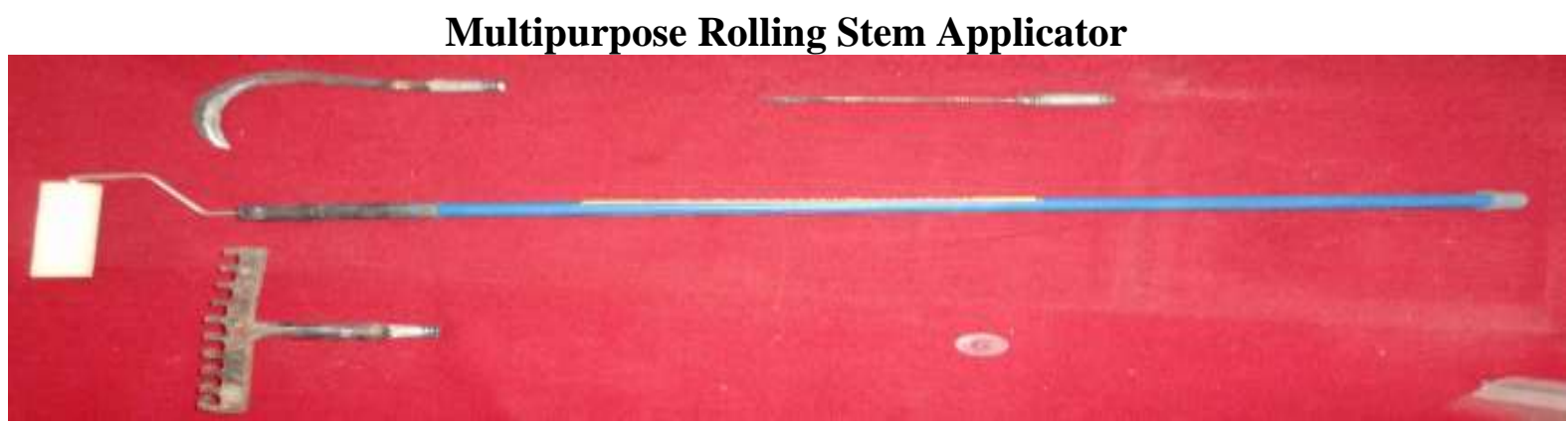

Fig.10

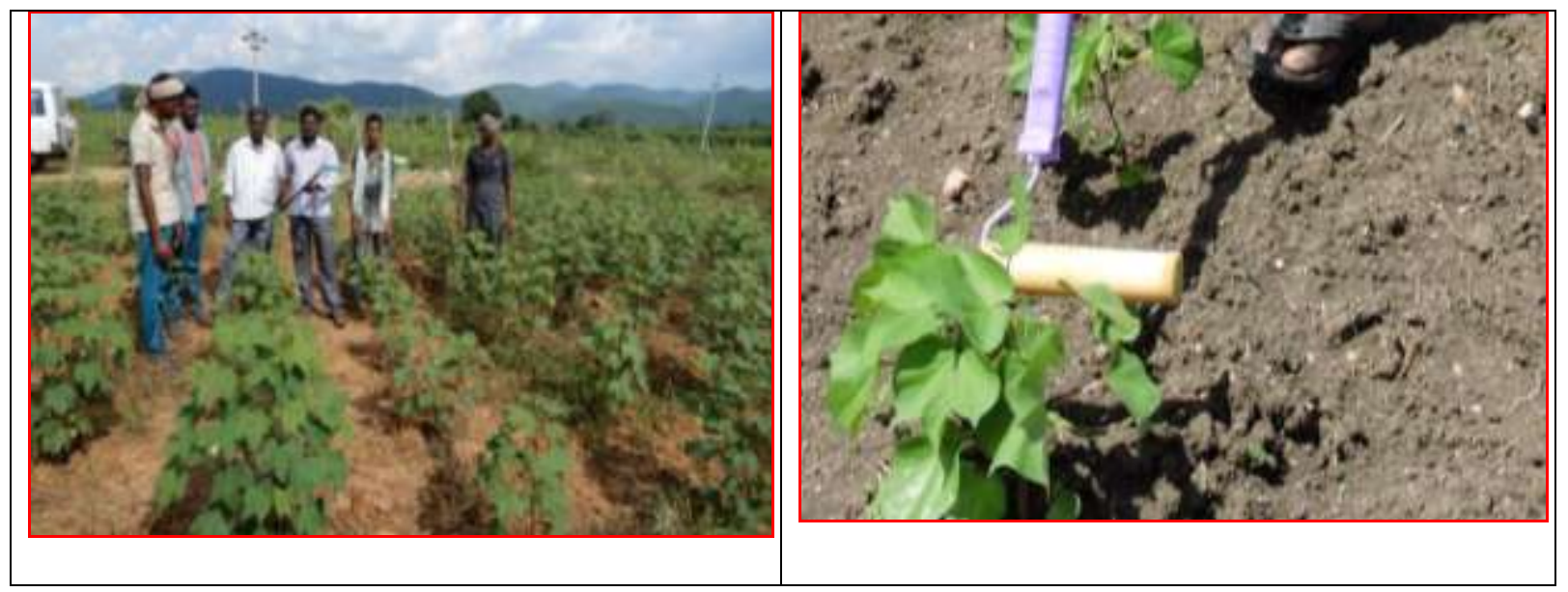

Fig.11

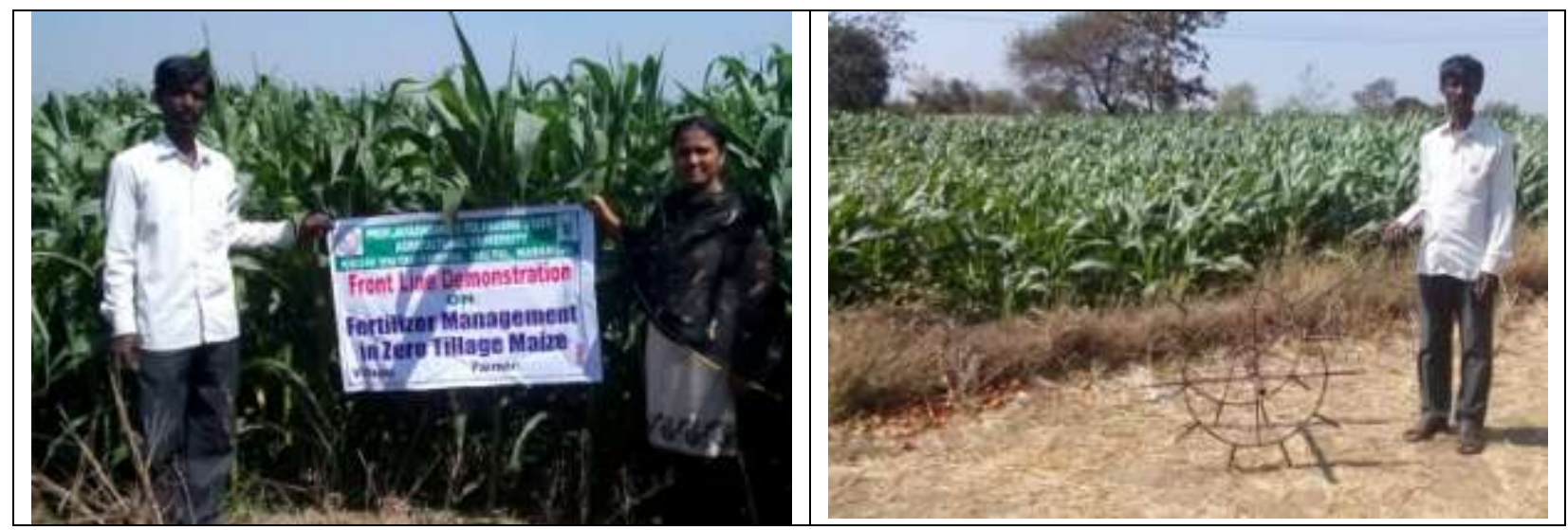

\section{References}

Cerdan, C.R., Rebolledo, M.C., Soto, G., Rapidel, B. and Sinclair, F.L. (2012). Localknowledge of Impacts of tree cover on ecosystem services in smallholder coffee production systems. Agricultural Systems 110: 119-130. Retrieved from http://www. sciencedirect.com/ science/article/pii/ 
S0308521X12000571.

Kelkar U, Narula KK, Sharma VP, Chandna U (2008) Vulnerability and adaptation to climate variability and water stress in Uttarakhand State, India. Glob Environ Change 18:564-574.

JayaKumara Vardhan, R. And Pramod Kumar. 2014. Indigenous Knowledge about climate change: Validating the perceptions of dryland famers in Tamil Nadu. Indian Journal of Traditional Knowledge, Vol13, April 2014, pp.390397.

Meera, Shaik N., V. Balaji, P muthuraman B. Sailaja, and Sreenath Dixit. " Changing Roles of Agricultural Extension: Harnessing Information and Communication Technology (ICT) for Adapting to Stresses Envisaged Under Climate Change" In: Venkateswarlu, B., Shankar, A.K., Shankar, C., Maheswari, M. (Eds), Crop Stress and its management: Perspectives and Strategies, Spring Netherlands.

Raji Reddy, D., Dakshina Murthy, K.M., Mahadevappa, S.G., Sreenivas, G. and Sunitha Devi, R. 2013. " Role of Agricultural Extension in disseminating agro advisories in mitigating climate change impacts". Compendium of National Seminar on Futuristic Agricultural Extension for livelihood improvement and sustainable development, January 19-21, 2013, ANGRAU, Hyderabad, 279-287.

Rao, V.U.M., Bapuji Rao, B., Khandgonda, I.R., Rao, A.V.M.S., Vijay Kumar, P.Dagar, J.C. and Venkateswarlu, B. (2011). Perception of Indian Farmers on Climate Change - An Assessment and Awareness Programme. Central
Research Institute for Dryland Agriculture, Santhoshnagar, Hyderabad, India.33p.

Rupan, R., Saravanan, R. and Suchiradipta, B. 2018. Climate Smart Agriculture and Advisory Services: Approaches and Implication for Future. MANAGE Discussion Paper 1, MANAGE- Centre for Agricultural Extension Innovations, Reforms and Agripreneurship (CAEIRA), National Institute of Agricultural Extension Management, Hyderabad, India.

Rupsha, R. and Banerjee, R. 2014. Farmers' perception of climate change, impact and adaptation strategies: a case study of four villages in the semi-arid regions of India. Natural Hazards Journal of the International Society for the Prevention and Mitigation of Natural Hazards, ISSN 0921-030X, Nat Hazards DOI 10.1007/s11069-014-1466-z.

Shankara, M., Shivamurthy, M. and Vijaya Kumar, K.T. 2013. Farmers perception on climate change and its impact on agriculture in eastern dry zone of Karnataka. International Journal of Farm Sciences 3(2):100-107, 2013.

Venkateswarlu, B.and Shankar, A.K. 2009.Climate change and Agriculture:Adaptation and mitigation strategies. Indian Journal of Agronomy, 54:226-230

Venkateswarlu, B. "Technology dissemination for climate resilient agriculture" Compendium of National Seminar on Futuristic Agricultural Extension for livelihood improvement and sustainable development, January 19-21, 2013, ANGRAU, Hyderabad, 39-45.

\section{How to cite this article:}

Raji Reddy, D. and Savitha, B. 2019. Mitigating Climate Change Impact through Technology Dissemination. Int.J.Curr.Microbiol.App.Sci. 8(10): 823-834.

doi: https://doi.org/10.20546/ijcmas.2019.810.095 